\title{
BMJ Global Health Health impact of human rights testimony: harming the most vulnerable?
}

\author{
Susan M Meffert, ${ }^{1}$ Shonali Shome, ${ }^{2}$ Thomas C Neylan, ${ }^{1}$ Karen Musalo, ${ }^{3}$ \\ Harvey V Fineberg, ${ }^{4}$ Molly M Cooke, ${ }^{5}$ Paul A Volberding, ${ }^{5}$ Eric P Goosby ${ }^{5}$
}

To cite: Meffert SM, Shome S, Neylan TC, et al. Health impact of human rights testimony: harming the most vulnerable?. BMJ Global Health 2016;1: e000001. doi:10.1136/ bmjgh-2015-000001

SMM and SS are joint first authors.

Received 20 October 2015 Revised 9 May 2016 Accepted 24 May 2016

CrossMark

${ }^{1}$ Department of Psychiatry, University of California San Francisco (UCSF), San Francisco, California, USA

${ }^{2}$ Legal and Gender Advisor, AIDS, Uniondale, New York, USA

${ }^{3}$ Center for Gender and Refugee Studies, UC Hastings College of the Law,

San Francisco, California, USA

${ }^{4}$ Gordon and Betty Moore Foundation, Palo Alto, California, USA

${ }^{5}$ Department of Medicine, University of California San Francisco (UCSF), San Francisco, California, USA

Correspondence to Dr Susan M Meffert; Susan.Meffert@ucsf.edu

\section{ABSTRACT}

Background: Current legal efforts to document human rights violations typically include interviews in which survivors are asked to provide detailed descriptions of their traumatic experiences during a single meeting. Research on similar interview techniques used as part of a mental health treatment (eg, debriefing) has raised concerns that they might worsen mental health-more than doubling the risk of post-traumatic stress disorder in some studies. While controversy over the mental health impact of debriefing continues, debriefing treatments have been discontinued in most clinics nearly 2 decades ago. The purpose of this article is to promote the development and integration of preventative measures to limit potential mental health damage associated with legal endeavours to address human rights violations and international crimes.

Methods and findings: Given the recent growth of the field of global mental health and its current capacity to provide feasible, acceptable, effective care in low-resource settings, we propose a research agenda to identify the mental health impact of current human rights legal practices and test a model of scalable medicolegal care that minimises risk by integrating mental health monitoring and applying upto-date models of trauma treatment, including multiple meeting sessions, as indicated.

Conclusions: As the fields of global health, human rights law, international criminal law and transitional justice increasingly overlap in their efforts to assist communities affected by grave violence, we propose that synchronising efforts may offer important opportunities to improve mental health for survivors.

\section{INTRODUCTION}

More than two decades ago, research suggested that describing one's traumatic experiences in a detailed one-session manner, as often required for legal documentation, increased the risk of chronic post-traumatic stress disorder (PTSD) - an extremely disabling mental disorder associated with all-cause mortality, violence towards others, depression and substance abuse. In the mid-1990s,

\section{Key questions}

What is already known about this topic?

- Describing emotionally traumatic experiences in detail over a single meeting, may increase the risk of post-traumatic stress disorder.

- The expanding role of global legal aid organisations working with survivors of human rights violations often includes gathering the details of victimisation in single meetings with survivors.

- The field of global mental health now has proven methods for effectively treating trauma-related mental disorders in low-resource settings, using local, non-specialist personnel.

\section{What are the new findings?}

- We bring global health researchers and human rights attorneys together to describe a novel implementation research agenda to advance integrated models of mental health recovery and human rights law.

\section{Recommendations for policy}

- Global health and human rights law share an interconnected commitment to disenfranchised populations in low-resource settings. In order to improve care for individuals and advance implementation strategies for lasting policy change, global health workers must engage with their legal counterparts.

mental healthcare for prevention of PTSD included a type of treatment called 'debriefing'. This treatment consisted of a single meeting in which a survivor of a recent traumatic event was asked to retell the events in detail to a mental health professional. Research on debriefing found, that rather than preventing PTSD, debriefing more than doubled the risk of persistent PTSD 1 year later, and the same heightened risk of PTSD was still present 3 years later, the longest available follow-up period. ${ }^{1}{ }^{2}$ While the findings of these studies are controversial, based on concerns regarding their design, analyses 
and interpretation, ${ }^{3} 4$ debriefing has been eliminated as a recommended treatment for traumatised individuals in most clinical settings.

In contrast, Mollica, ${ }^{5}$ Jones and Kafetsios ${ }^{6}$ described the complexity of emotional responses among traumatised human rights survivors and the need for culturally informed, gradual review of the trauma 'story' or 'narrative' with adults and adolescents. Subsequently, prolonged exposure therapy, which involves a measured review of the trauma narrative over many sessions (averaging 10 sessions of $90 \mathrm{~min}$ ) has become a current 'gold standard' in PTSD psychological treatments. ${ }^{7}$

\section{Legal context}

Human rights legal efforts have proliferated over the past several decades and there are now organisations devoted to providing extensive documentation of human rights law enforcement in most parts of the world. International criminal law has also developed significantly in recent years: the International Criminal Court (ICC) was established in 2002, and is the world's first permanent court with jurisdiction over genocide, war crimes and crimes against humanity. While the ICC does provide psychological support, including services from the Victims and Witnesses Unit and the Trust Fund for Victims (TFV) for the 'victim-witnesses' who travel to The Hague to provide testimony, and to groups of in-country survivors (TFV), the majority of the victims providing testimony for the ICC are 'victim-participants' who testify without leaving their country of origin. For victim-participants, the mechanisms for supporting mental health before, during and after the process of providing testimony are unclear, nor even mentioned in the ICC guide for prospective victim-participants and their assistants. ${ }^{8}$

Leading human rights organisations are alert to the dangers of retraumatising survivors during interviews, and many have published 'best practice' guidelines which reference the need to avoid retraumatisation. One of the prominent early guidelines was the 1999 Istanbul Protocol: a manual on the Effective Investigation and Documentation of Torture and Other Cruel, Inhuman or Degrading Treatment or Punishment, published by the United Nations Office of the High Commissioner for Human Rights, ${ }^{9}$ which concluded a section devoted to 'Risk of re-traumatization of the Interviewee' by stating: 'Despite all precautions, physical and psychological examinations by their very nature may re-traumatize the patient by provoking or exacerbating symptoms of posttraumatic stress by reviving painful effects and memories.' The ICC published regulations in 2009 asserting:

The physical and psychological well-being of persons who are questioned by the Office and are considered vulnerable (in particular children, persons with disabilities and victims of gender and sexual crimes) shall be assessed by a psychology, psycho-social or other expert during a face-to-face interview prior to questioning. This assessment shall determine whether the person's condition at that particular time allows him or her to be questioned without risk of re-traumatisation.

Other prominent organisations such as Human Rights Watch, Amnesty International and WHO, have also published guidelines intended to avoid retraumatisation of interviewees. $^{10-12}$ While these guidelines reflect sensitivity to the potential mental health impact of investigations on survivors of human rights violations, we are not aware of any requirements to monitor or report the actual mental health impact of the investigations. As noted by Amon et al, ${ }^{13}$ many human rights research organisations do not engage research ethics committees or view human rights documentation as research. With the exception of some organisations which have created their own internal review boards, many human rights organisations do not submit their study plan for independent human subjects protection review, or submit progress reports, with monitoring for, and reporting of, adverse events.

\section{Medical context}

At the time when global human rights legal endeavours began, the field of global mental health (GMH) had not yet been founded. Now, the huge burden of mental disorders suffered in low and middle income countries is not debatable. $^{14}{ }^{15}$ Also, it is not debatable that common mental disorders, including those occurring in the context of traumatic experiences, can be effectively treated in low-resource settings. GMH has evidence-based methods of measuring mental health status across diverse cultural settings, assessing mental healthcare needs and adapting evidence-based treatments such that they are locally acceptable and feasible, as well as effective, using low-cost, scalable delivery models. ${ }^{16-18}$ Despite the content similarities discussed above, it is possible that the short-term and/or long-term emotional impact of providing legal testimony is different from that of 'debriefing'. Given that we now have the ability to deliver evidencebased mental healthcare in low-resource settings and partner for sustained scale-up of evidence-based care where few services have previously existed, evaluating for remediable mental health impact has potential benefits for survivors of human rights violations.

Institutional review boards (IRBs) have been used to approve and monitor biomedical and behavioural research involving human subjects in the USA since 1974. Reacting to abuses by Nazi physicians and the Tuskegee Syphilis study, the goal of IRBs is to protect the rights and welfare of human subjects according to the principles of 'respect for persons', 'beneficence' and 'justice'. ${ }^{19}$

\section{TENSION BETWEEN CLINICAL AND LEGAL GOALS FOR SURVIVORS}

Setting a collaborative research agenda

While the parallels between debriefing and providing testimony are concerning in regards to potential mental 
health impact on the survivors of human rights violations, the topic requires more study for two reasons: ${ }^{1}$ there remains substantial controversy regarding the actual mental health impact of debriefing, and ${ }^{2}$ differences between legal and medical context may produce different mental health impacts even when the same strategies are used. Indeed, there is a body of legal literature theorising that empowering legal processes, including testifying, can be part of reparative justice that leads to emotional healing on an individual level for the survivors who provide their trauma narrative. ${ }^{20-23}$ The South African Truth and Reconciliation Commission, a wellknown example of transitional justice, asserted that 'revealing is healing'-expressing the belief that exposing the details of personal traumas promotes healing for individuals and the nation. However, to date, there is little to no evidence on the specific impact of providing legal testimony, despite the concerns that research on debriefing raises, and harms that are theorised. ${ }^{24}$ Weinstein and Stover, early investigators of the impact of international criminal law on individuals, surmised that the assumed 'therapeutic value' of human rights processing may be 'more wishful thinking than fact'. 25

While medical and legal processes typically operate separately with different goals, we argue that current assumptions regarding the ability of legal testimony to promote psychological healing cross into the territory of health professionals. Indeed, some practices in human rights law, international criminal law and transitional justice bear a strong resemblance to critical incident debriefing, which is now widely regarded as a risk to mental health. Given the growth of the field of GMH and our present ability to provide evidence-based, effective, sustainable mental health treatment to trauma survivors in low-resource settings, we assert an imperative need to investigate and address the mental health impact of these practices. This opinion is in line with expert opinion that the current lack of evaluation and research on mental health in emergency settings is unethical. ${ }^{26}$ For the purposes of this manuscript, we use victim-participants at the ICC as a case example to illustrate where and how this research could be implemented. However, there is a need for this research, and investigation across the fields of human rights law, international criminal law and transitional justice, and the proposed model could be used with UN human rights bodies, regional human rights commissions and courts, truth, justice and reconciliation commissions and the vast number of national and international nongovernmental organisations around the world who frequently interview survivors of human rights abuses and international crimes.

\section{ICC as a case example}

In 2002, the Rome Statute established the ICC with a mandate to address to the international community the most serious crimes of concern, such as genocide, war crimes and crimes against humanity. While the ICC can support only a relatively small number of 'victimwitnesses' to provide legal testimony in The Hague, there are comparatively large numbers of victimparticipants, who provide their narratives without leaving their country of origin. As of April 2012, in total, nearly 20000 victim-participant applications had been received by the ICC, with a 300\% rise between 2011 and 2012 .

\section{Proposed research agenda: ICC}

Phase 1: information access and epidemiology—define the problem

The first step is to better define the health impact of the ICC's processes for gathering testimony across a range of ICG victim-participant processes and sites. The assessment team could measure the mental health impact of providing testimony to an ICC representative by applying low-burden mental health assessment tools in a low-cost manner using local paraprofessionals (eg, Patient Health Questionnaire-9 (nine items), Primary Care PTSD screen (four items). ${ }^{27} 28$ Measures could be applied at baseline with prospective ICC victim-participants, and again after they provide their trauma narrative to the ICC representative to test the hypothesis that providing testimony is associated with worsened mental health. Using a mixedmethods design, this quantitative assessment data could be augmented with qualitative interviews before and after testimony regarding expectations/hopes and experiences/mental health impact, respectively. By combining mental health assessment data with demographics and relevant contextual details, risk and protective factors for mental health, the following testimony may be identified. The results of this phase 1 research would provide important prospective data on the mental health impact of providing testimony to the ICC.

\section{Phase 2: monitoring and intervention-IRBs, informed} consent, screening tools and mental health interventions Using data generated from phase 1 research, proposed human rights documentation studies could be submitted to the in-country IRB approval mechanism for biomedical/behavioural research, with use of mental health assessment tools for monitoring, reporting and managing adverse events. Correspondingly, human rights study individuals could participate in an informed consent process that includes the risk to health posed by relaying a detailed trauma narrative in a condensed manner.

A mental health intervention could be tailored to meet the needs of victim-participant groups (figure 1). An initial intervention is simply to substitute the ICC word survivor-participants for the word victimparticipant. This semantic change took place nearly a decade ago in the field of mental health trauma care to empower individuals toward recovery. At the first meeting, survivors could undergo a mental health screening - those who are highly symptomatic, or at high risk of decompensation, could be scheduled for mental health trauma care (multisession) prior to legal interaction. Survivors could name a trusted contact to be 


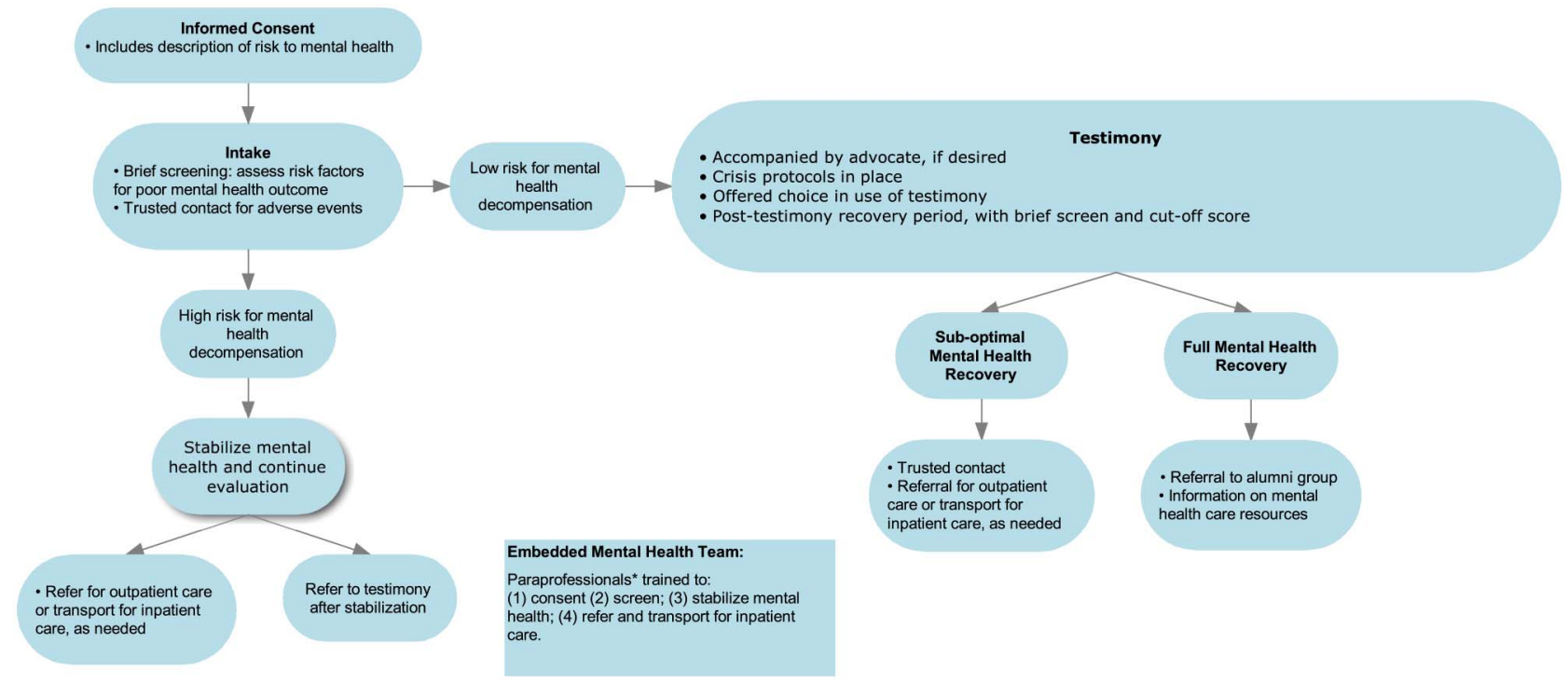

Figure 1 Model for integration of Mental Healthcare with Documentation of Human Rights Violation: an Embedded Paraprofessional Mental Health Assessment Team. *There is now a strong body of evidence showing that local paraprofessionals in Low and Middle Income Countries (LMICs) can be efficiently trained to screen and effectively deliver evidence based mental health treatments, such as brief, structured psychotherapies (eg, Interpersonal Psychotherapy (IPT)) in a cost-effective manner.

used in the event of overwhelming emotional distress, and an advocate, such as a healthy community member who completed ICC Victim Participant testimony, could be offered as a supporter who accompanies survivors through the process of providing testimony. Survivors could be offered a choice in how their stories are used and how long they are stored. After providing testimony, survivors could be monitored for recovery with a follow-up mental health screen, and referred for higher-level care, as needed. This mental health monitoring/intervention model could be tested for efficacy with a clustered RCT design of integrated mental health monitoring/treatment versus treatment as usual, testing the hypothesis that providing mental healthcare to those who meet criteria for depression and/or trauma-related disorders will decrease their risk of mental health decompensation following provision of testimony.

Phase 3: effectiveness, implementation and scale-up through policy

Depending on the results from phases 1 and 2, the next phase of the work is effectiveness and implementation research to ascertain generalisability of the intervention, conduct cost-benefit analyses and work with policymakers for scale-up. Specifically, this phase of research could test the hypothesis that providing mental healthcare for individuals who are giving ICC victim-participant testimony, and have depression or trauma-related disorders, would be cost-effective and produce a net economic gain by reducing mental health-related disability early in the course of disease.

\section{CONCLUSIONS}

The purpose of this article is to promote the development and integration of preventative measures to limit potential mental health damage associated with legal endeavours to address human rights violations and international crimes. Although we express concerns about the potential health impact of the ICC's current engagement with victim-participants, we applaud its focus on survivors and understand that the pioneering effort of the ICC is a work in progress. We include the ICC as only one case example of where this proposed research is needed and would be applicable. As the fields of global health, human rights law, international criminal law and transitional justice increasingly overlap in their efforts to assist communities affected by grave violence, we propose that synchronising efforts may offer important opportunities to improve mental health for survivors.

\section{Handling editor Seye Abimbola}

Acknowledgements The authors would like to thank Dr Harvey Weinstein, Dr Stephen Smith Cody and Dr Kim Thuy Seelinger for their discussion of this manuscript.

Contributors SMM and SS are joint first authors on this manuscript and wrote the manuscript. TCN provided substantial input to the conceptual and editorial revisions of earlier drafts. KM, HVF, MMC, PAV contributed to the conceptual and editorial revisions of earlier drafts. EPG provided critical conceptual guidance on initiation, development and publication of this manuscript.

Competing interests None declared.

Provenance and peer review Not commissioned; externally peer reviewed.

Data sharing statement No additional data are available.

Open Access This is an Open Access article distributed in accordance with the Creative Commons Attribution Non Commercial (CC BY-NC 4.0) license, which permits others to distribute, remix, adapt, build upon this work non- 
commercially, and license their derivative works on different terms, provided the original work is properly cited and the use is non-commercial. See: http:// creativecommons.org/licenses/by-nc/4.0/

\section{REFERENCES}

1. Mayou RA, Ehlers A, Hobbs M. Psychological debriefing for road traffic accident victims. Three-year follow-up of a randomised controlled trial. Br J Psychiatry J Ment Sci 2000;176:589-93.

2. Bisson JI, Jenkins PL, Alexander J, et al. Randomised controlled trial of psychological debriefing for victims of acute burn trauma. Br J Psychiatry J Ment Sci 1997:171:78-81.

3. Ekeberg O, Hem E. Psychological debriefing-does it never work? Br J Psychiatry J Ment Sci 2001;178:182-3.

4. Bastian $\mathrm{H}$. PubMed commons comment on: randomised controlled trial of psychological debriefing for victims of acute burn trauma. NCBI, 2013 (cited 5 May 2016). http://www.ncbi.nlm.nih.gov/ pubmed/9328501\#cm9328501 142

5. Mollica RF. The trauma story: the psychiatric care of refugee survivors of violence and torture. In: Ochberg FM, ed. Post-traumatic therapy and victims of violence. Psychology Press, 1988:295-350.

6. Jones L, Kafetsios K. Assessing adolescent mental health in war-affected societies: the significance of symptoms. Child Abuse Negl 2002;26:1059-80.

7. Mørkved N, Hartmann K, Aarsheim LM, et al. A comparison of Narrative Exposure Therapy and Prolonged Exposure therapy for PTSD. Clin Psychol Rev 2014;34:453-67.

8. BOOKLET-160910VPRSBookletEnglish.pdf [Internet]. (cited 10 February 2016). https://www.icc-cpi.int/NR/rdonlyres/ 8FF91A2C-5274-4DCB-9CCE-37273C5E9AB4/282477/ 160910VPRSBookletEnglish.pdf

9. United Nations. The Istanbul Protocol: manual on the effective investigation and documentation of torture and other cruel, inhuman or degrading treatment or punishment. New York, 1999 (cited 7 January 2016). http://www.ohchr.org/Documents/Publications/ training8Rev1en.pdf

10. About Our Research I Human Rights Watch [Internet] (cited 11 February 2016). https://www.hrw.org/about-our-research\#4

11. World Health Organization. WHO ethical and safety recommendations for researching, documenting and monitoring sexual violence in emergencies. Geneva: World Health Organization, 2007.

12. Part 4: suggestions for interviews. In: Ukweli: monitoring and documenting human rights violations in Africa: a handbook / CODESRIA. Dakar: CODESRIA, 2000 (cited 11 February 2016). http://www.codesria.org/spip.php?article586

13. Amon JJ, Baral SD, Beyrer C, et al. Human rights research and ethics review: protecting individuals or protecting the state? PLoS Med 2012;9:e1001325.

14. Whiteford HA, Degenhardt L, Rehm J, et al. Global burden of disease attributable to mental and substance use disorders: findings from the Global Burden of Disease Study 2010. Lancet 2013;382:1575-86.
15. World Health Organization. World Health Organization Mental Health Action Plan: 2013-2020 [Internet]. Geneva: WHO Press, 2013 (cited 6 May 2016). http://apps.who.int/iris/bitstream/10665/89966/1/ 9789241506021_eng.pdf

16. Bass JK, Annan J, Mclvor Murray S, et al. Controlled trial of psychotherapy for Congolese survivors of sexual violence. N Engl J Med 2013;368:2182-91.

17. Bolton $\mathrm{P}, \mathrm{Bass} \mathrm{J}$, Betancourt $\mathrm{T}$, et al. Interventions for depression symptoms among adolescent survivors of war and displacement in northern Uganda: a randomized controlled trial. JAMA J Am Med Assoc 2007;298:519-27.

18. van Ginneken N, Tharyan P, Lewin S, et al. Non-specialist health worker interventions for the care of mental, neurological and substance-abuse disorders in low- and middle-income countries. Cochrane Database Syst Rev 2013; 11:CD009149.

19. Department of Health, Education and Welfare. The Belmont Report: Office of the Secretary Ethical Principles and Guidelines for the Protection of Human Subjects of Research The National Commission for the Protection of Human Subjects of Biomedical and Behavioral Research [Internet]. 1979 (cited 9 May 2016). http://www. hhs.gov/ohrp/regulations-and-policy/belmont-report/

20. Doak J. The therapeutic dimension of transitional justice: emotional repair and victim satisfaction in international trials and truth commissions. Int Crim Law Rev 2011;11:263-98.

21. The International Criminal Court and its relevance to affected communities. In: Waddell N, Clark P, eds Courting conflict-justice, peace and the ICC in Africa. London: Crisis States Research Centre 2008 (cited 12 December 2014). https://www.scribd.com/doc/ 65051634/Courting-Conflict-Justice-Peace-and-the-Icc-in-Africa

22. Danieli Y. Massive trauma and the healing role of reparative justice. J Trauma Stress 2009;22:351-7.

23. Agger I, Bisimwa S, Chy T, et al. Independent Panel of Experts Report on Victim Participation at the International Criminal Court. Amnesty International; 2013.

24. Henry $\mathrm{N}$. The impossibility of bearing witness: wartime rape and the promise of justice. Violence Against Women 2010;16:1098-119.

25. Stover E. Witnesses and the promise of justice in The Hague. In: Weinstein HM, Stover E, eds. My neighbor, my enemy: justice and community in the Aftermath of Mass Atrocity. Cambridge University Press, 2004:104-20.

26. Allden $\mathrm{K}$, Jones $\mathrm{L}$, Weissbecker I, et al. Mental health and psychosocial support in crisis and conflict: report of the Mental Health Working Group. Prehospital Disaster Med 2009;24(Suppl 2): S217-27.

27. Kroenke K, Spitzer RL, Williams JBW. The PHQ-9: validity of a brief depression severity measure. J Gen Intern Med 2001;16:606-13.

28. Prins A, Ouimette P, Kimerling R, et al. The Primary Care PTSD Screen (PC-PTSD): development and operating characteristics. Prim Care Psychiatry 2003;9:9-14. 